\title{
Um século de teatro em Portugal
}

\section{António Braz Teixeira}

Luiz Francisco Rebello, Três espelhos. Uma visão panorâmica do teatro português do liberalismo à ditadura (1820-1926), Lisboa, Imprensa Nacional-Casa da Moeda, Temas Portugueses, 2010, 576 pp.

Luiz Francisco Rebello (n. 1924) é, há mais de seis décadas, figura central e decisiva da vida teatral portuguesa, como um dos principais renovadores da nossa literatura dramática e como crítico e historiador do nosso teatro, de que é, de há muito, a mais reconhecida autoridade.

Desde a sua participação, em 1946, na fundação do Teatro Estúdio do Salitre, onde, no ano seguinte, se estreou a sua "fábula" num acto 0 mundo começou às 5 e 47, de matriz ainda expressionista, ao recente 0 órfão de Deus (2004-2005), ao longo de sessenta anos e vinte e três textos teatrais (reunidos em dois volumes de Todo o teatro (Lisboa, INCM, 1999 e 2006), em que avultam peças tão significativas como 0 dia seguinte (1949), Alguém terá de morrer (1954), É urgente o amor (1957), Os pássaros de asas cortadas (1958), Condenados à vida (1963), Portugal, anos 40 (1982) ou A desobediência (1995), Luiz Francisco Rebello consolidou uma posição indiscutivel de primeiro

António Braz Teixeira

é jurista, filósofo e

docente universitário, tendo-se destacado no estudo da Filosofia do Direito e, em geral, $n$ reflexão sobre a Filosofia Portuguesa.

Ocupou cargos

públicos, tendo sido

Secretário de Estado da

Cultura, Director do

Teatro Nacional

D. Maria 11, Vice-

Presidente do Conselh de Gerência da

Radiotelevisão

Portuguesa e, mais recentemente,

Presidente da Imprensa Nacional - Casa da

Moeda, onde

dinamizou a publicação

de livros de e sobre teatro, bem como obras

de pensadores e filósofos portugueses e brasileiros. plano na dramaturgia portuguesa contemporânea.

A sua obra, pela sua sólida modernidade, conserva uma invulgar actualidade, devido, por um lado, à sua funda reflexão antropológico-metafísica sobre a condição e o destino do homem, centrada na análise ou na dimensão do microcosmo familiar e, por outro, à sobriedade e naturalidade da linguagem das suas peças, à densidade e à verdade humana e psicológica das suas personagens, ao seu profundo sentido teatral e à hábil condução da acção dramática.

Paralelamente a esta actividade de criação dramatúrgica, desenvolveu o autor de 0 fim na última página um igualmente intenso trabalho no domínio, até então relativamente pouco explorado, da investigação da história do teatro português, iniciado com o ensaio sobre D. João da Câmara, publicado no segundo volume da Perspectiva da literatura portuguesa do século XIX (1948) dirigida por João Gaspar Simões, e prosseguido com obras igualmente relevantes e pioneiras como Teatro português, do romantismo aos nossos dias (1960), Breve história do teatro português (1968), O primitivo teatro português (1977), O teatro naturalista e neo-romântico (1979), 0 teatro simbolista e modernista (1979), 0 teatro romântico em Portugal (1980), História do teatro de revista em Portugal (1984- 1985) ou O teatro de Camilo (1991), a que há que acrescentar as diversas antologias que organizou, prefaciou e anotou, como os três volumes de Teatro português em um acto (1997, 2003 e 2007) ou do Teatro

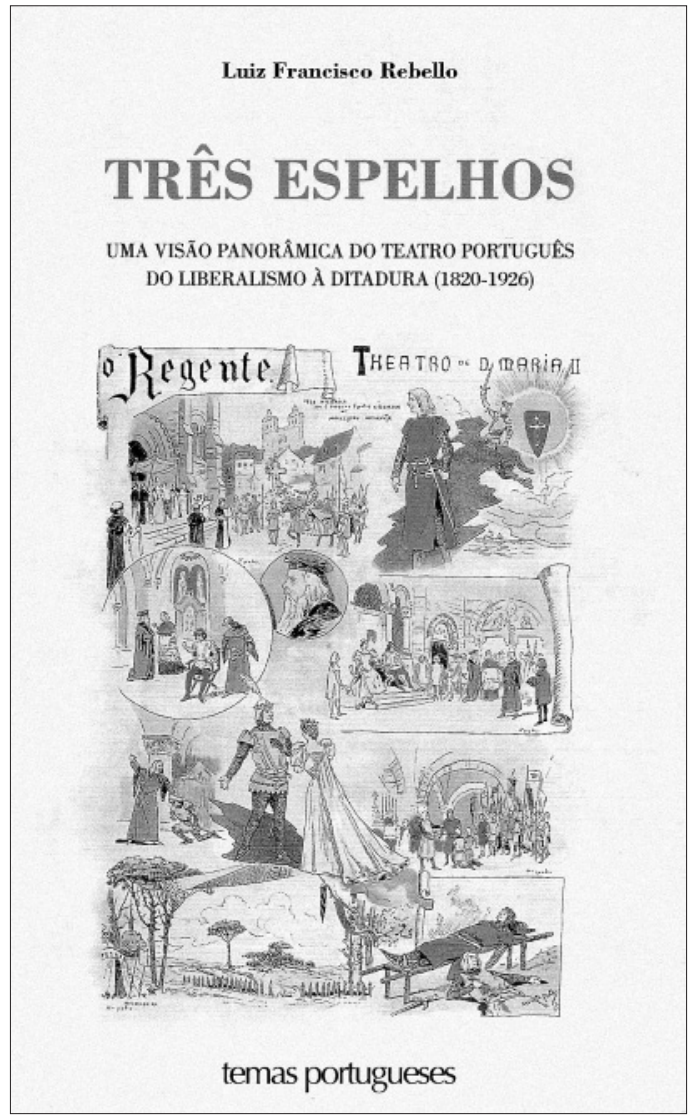

romântico português. 0 drama histórico (2007), primeiro de uma série que cobrirá todo o século XIX e o início do seguinte.

Uma terceira vertente da múltipla actividade de Luiz Francisco Rebello diz respeito à divulgação crítica do teatro contemporâneo, começada com o volume (também acompanhado de esclarecedora antologia) Teatro moderno: caminhos e figuras (1957), a que se sucederam Imagens do teatro contemporâneo (1961), o jogo dos homens (1971), Fragmentos de uma dramaturgia (1994) e 0 palco virtual (2004), cabendo não esquecer o interessante volume de memórias 0 passado na minha frente (2004), que contém abundante informação sobre mais de meio século de vida teatral e cultural portuguesa, bem como a relevantíssima acção que desenvolveu, durante mais de trinta anos, como presidente da Sociedade Portuguesa de Autores ou no campo do direito de autor, de que continua a ser o nosso maior e mais experimentado especialista.

A simples consideração dos títulos que compõem a sua bibliografia não poderá deixar de concluir que, sem prejuizo de haver procurado atender ao integral trajecto histórico do teatro português, desde o seu início, nos 


\section{teatro moderno}

camintos e figuras

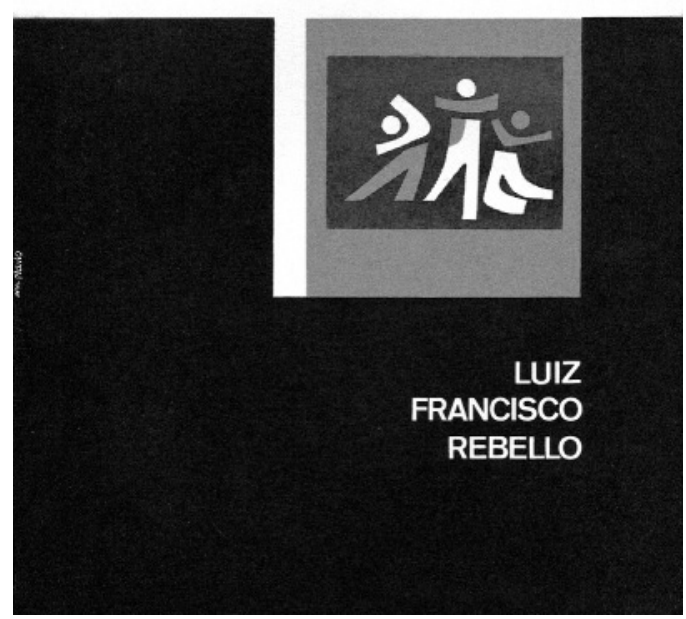

\section{LUIZ FRANCISCO REBELLO}

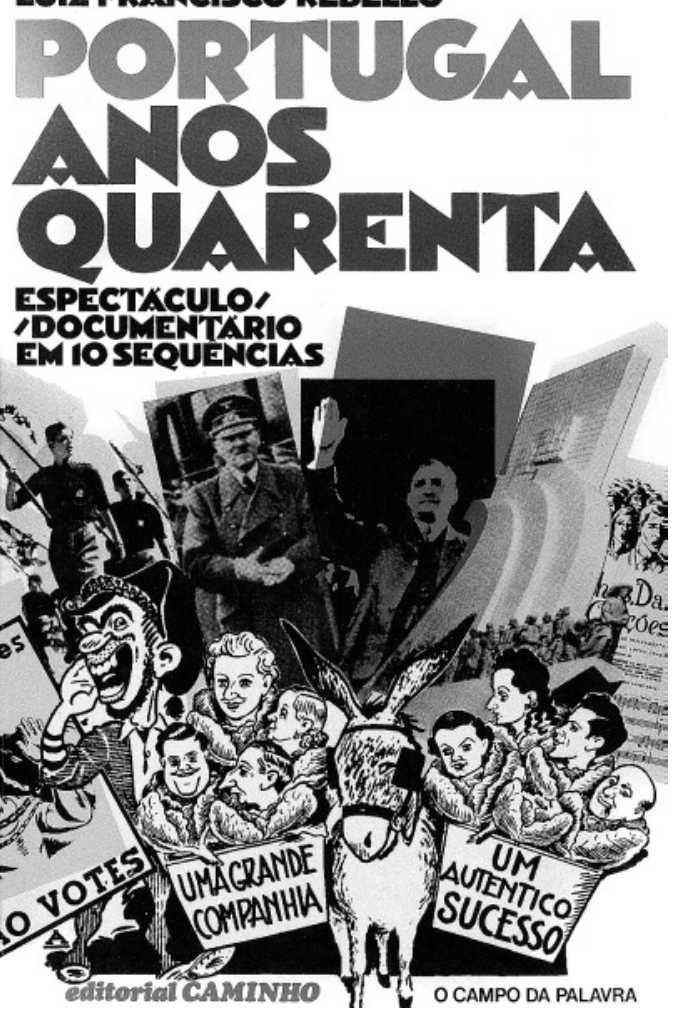

séculos medievais, até à mais recente actualidade, a atenção historiográfica e hermenêutica de Luiz Francisco Rebello privilegiou os últimos dois séculos, com particular destaque para o tempo que decorreu desde o triunfo da revolução liberal de 1820 até meados do século findo.

É, precisamente, de quase todo este período que se ocupam as cerca de seis centenas de páginas deste Três espelhos, cujo subtítulo esclarece tratar-se de uma "visão panorâmica do teatro português do liberalismo à ditadura (1820-1926)".

Justificando o título escolhido para esta brilhante sintese sobre cem anos de teatro português, lembra, preambularmente, o autor que a "metáfora do teatro como espelho (...), explícita ou implícita, é transversal a toda a história da arte dramática", sendo para ela que remete a mimesis aristotélica, definida, na Poética do Estagirita, como "imitação ou reprodução duma acção (praxis) ou conjunto de acções estruturadas numa fábula (mythos)", noção que, para Luiz Francisco Rebello, além de se apresentar como nuclear nas dramaturgias ocidentais, não é delas exclusivo, uma vez que se encontra, igualmente, nas manifestações teatrais do extremo oriente, apesar de estas se "regerem por outros códigos e se inscreverem noutros sistemas sígnicos".

Assim, prossegue o autor, "a relação ancestral entre o teatro e o mundo, o mesmo é dizer entre o espelho que reflecte e o objecto reflectido, analisa-se como uma relação dialéctica, em que a imagem será (...) a sintese resultante do confronto entre dois contrários". Deste modo o teatro, tendo embora a realidade como referente, não se confunde com ela nem a duplica e nem vem a substituí-la, mas interpela-a, atribuindo-Ihe um significado.

Cumpre não esquecer, no entanto, que o que há de específico no teatro ou no género dramático, marca indissolúvel da sua origem de celebração de natureza religiosa, é o ser elo, como disse Artaud, "um acto sagrado, que implica tanto aquele que o vê como aquele que o executa", é envolver, sempre, "uma relação triádica entre o texto, a cena e o público".

É esta ideia que explica a estrutura do presente volume, cuja primeira parte, dividida em três capítulos - o espelho retrovisor, o espelho reflector e o espelho translaticio se centra no texto dramatúrgico, na dimensão textual e literária do teatro ou na literatura dramática, enquanto a segunda, que se distribui, igualmente, por três capitulos - diz-se com música, os lugares da representação e os modos de representação - aborda as outras dimensões do acto teatral, desde o teatro musical ou musicado (opereta, mágica, revista), até aos teatros enquanto espaços de representação e aos actores e aos processos de representação.

Os três espelhos a que o título alude correspondem, 
respectivamente, ao teatro romântico, ao teatro naturalista / realista e ao teatro decadentista / simbolista, informando o autor consistir esta primeira parte do livro, em larga medida, numa refundição e ampliação dos volumes da infelizmente extinta Biblioteca Breve, editada pelo Instituto de Cultura e Língua Portuguesa (imediato antecessor do actual Instituto Camões) dedicados àqueles três momentos da nossa história teatral, bem como dos prefácios aos quatro volumes antológicos que preparou para a Imprensa Nacional-Casa da Moeda e de que, até à data, apenas o primeiro, dedicado ao drama histórico romântico, se encontra publicado.

Por outro lado, a concepção especular e espectacular do fenómeno teatral que preside à sua obra historiográfica e a relação substantiva que nela se estabelece ou pressupõe entre teatro e mundo, cuja realidade aquele reflecte, criadora e simbolicamente, explica que, como acontecia nos trabalhos anteriores de Luiz Francisco Rebello, a sua compreensão hermenêutica do sentido da realidade cultura que é o teatro não possa ignorar ou abstrair da concreta realidade social e política de cada tempo ou de cada época cujos traços essenciais são aqui enunciados ou lembrados, procurando o autor mostrar o modo como essa realidade se reflectiu no teatro e como este a reflectiu e, de certo modo, a viveu ou procurou agir criticamente sobre ela, visando corrigi-la, alterá-la ou transformá-la.

A parte mais inovadora deste volume, exigente e depurada condensação de toda uma vida de investigação, de constante reescrita e aperfeiçoamento de sínteses que se sabiam relativa e inevitavelmente provisórias, é a segunda, que procura alargar o respectivo âmbito a todas as dimensões do teatro como "obra de arte total" ou englobante. Se, como honestamente reconhece Luiz Francisco Rebello, há ainda aqui uma desproporção entre o espaço concedido a estas outras dimensões do teatro e o atribuido ao seu elemento literário ou textual, em claro benefício deste, isso deve-se, por um lado, à circunstância de, no período histórico aqui considerado, "o que prevalecia era uma concepção textocêntrica da prática teatral", e, por outro, à escassez de informação sobre a maioria dos restantes aspectos ou dimensões do teatro, como seja a que se refere aos actores ou aos modos de representação, matérias em que a investigação tem, necessariamente, de limitar-se a cotejar ou confrontar as apreciações exaustivas da crítica da época, uma vez que são praticamente inexistentes os registos fonográficos ou cinematográficos dos espectáculos.

Livro sintese e cume de uma vida generosamente dedicada ao "honesto estudo" da história do teatro português, estes Três espelhos, tal como a sua obra historiográfica anterior, passam a constituir fundamenta e impostergável obra de referência dos futuros estudos do nosso teatro e da nossa vida teatral no século que transcorreu entre a revolução liberal de 1820 e o fracasso da primeira experiência republicana, nele avultando as qualidades a que, de há muito, Luiz Francisco Rebello nos
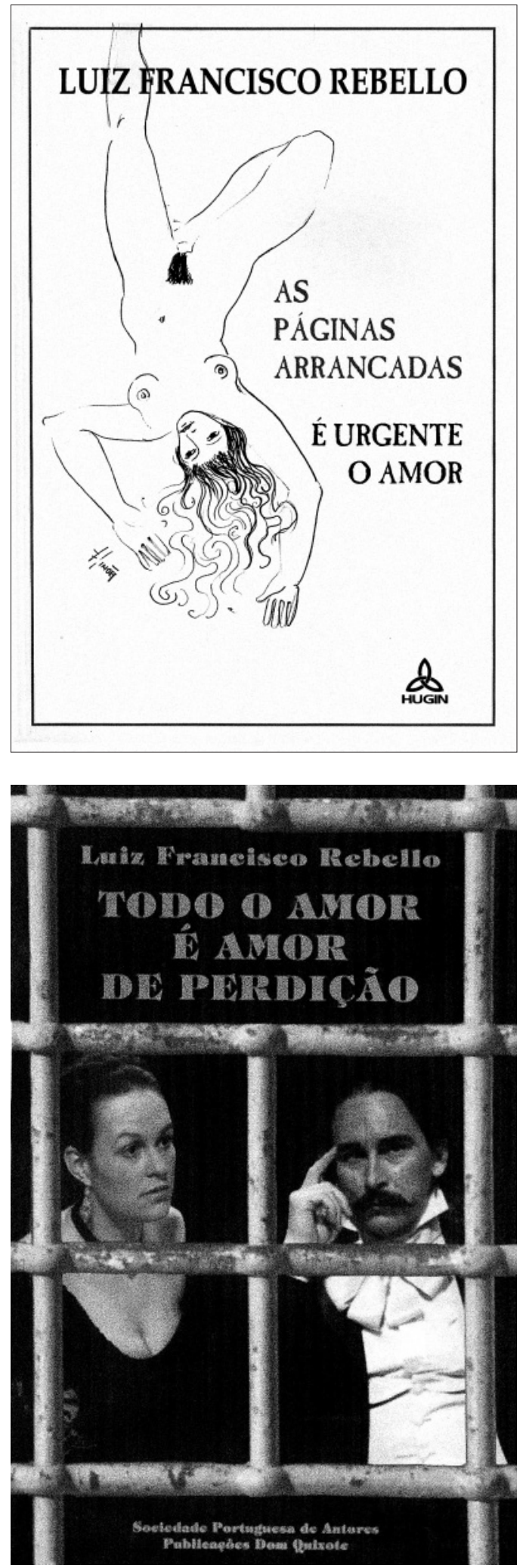

habituou: a clareza, o rigor e a elegância do estilo, pontuado de subtil e discreta ironia, o ponderado equilíbrio dos juizos, a atitude crítica empaticamente compreensiva da situação valorativa das obras e dos autores, o lúcido amor ao teatro que o leva a procurar resgatar de um injusto esquecimento alguns textos merecedores, ainda hoje, da prova decisiva do palco em que a vida imaginada se torna acto, no corpo e na voz dos actores. 